Received: 08.04.2021

Revised: 10.06 .2021

Accepted: 25.06 .2021

DOI: $10.17804 / 2410-9908.2021 .3 .017-030$

\title{
STUDYING THE CHEMICAL AND PHASE COMPOSITIONS OF A CHROMIUM-NICKEL-MANGANESE STEEL AFTER OPERATION AT ELEVATED TEMPERATURES IN CORROSIVE ENVIRONMENTS
}

\author{
N. B. Pugacheva, a) and B. N. Guzanov ${ }^{2, \text { b) }}$ \\ ${ }^{1}$ Institute of Engineering Science, Ural Branch of the Russian Academy of Sciences, \\ 34 Komsomolskaya St., Ekaterinburg, 620049, Russian Federation \\ ${ }^{2}$ Russian State Vocational Pedagogical University, \\ 11 Mashinostroiteley St., Ekaterinburg, 620012, Russian Federation \\ a) iD http://orcid.org/0000-0001-8015-8120 nat@imach.uran.ru; \\ b) iD http://orcid.org/0000-0001-5698-0018 guzanov_bn@mail.ru \\ *Corresponding author. E-mail: nat@imach.uran.ru \\ Address for correspondence: 34 Komsomolskaya St., Ekaterinburg, 620049, Russian Federation \\ Tel.: +7 (343) 36230 43; fax: +7 (343) 3745330
}

In recent years, chromium-nickel-manganese corrosion-resistant steels have been widely used in construction for the manufacture of stair railings and fences, elevators, and heat exchangers used for heat recovery in office premises and in production, including in metallurgical workshops. The purpose of this study is to determine the changes in the chemical and phase compositions of the $12 \mathrm{Cr} 15 \mathrm{Mn} 9 \mathrm{NiCu}$ corrosion-resistant steel (Russian analogue of the AISI 201 steel) after commercial operation in structural components of the heat exchanger of a metallurgical workshop. It was found that, during operation, all the studied fragments of the $12 \mathrm{Cr} 15 \mathrm{Mn} 2 \mathrm{NiCu}$ steel heat exchanger underwent intense oxidation with the formation of chromium and manganese oxides both on the surface and along the boundaries of the austenite grain. Diffusive penetration of sulfur into the steel with the formation of $\mathrm{MnS}$ particles, as well as carbonization of the surface layers, was recorded. As a result, the content of chromium and manganese in the steel significantly decreased, the amount of carbon increased, and the structure changed from austenitic to martensitic with a hardness of 532 HV 5 (48 HRC). Several investigated fragments retained austenite with oxidized grain boundaries. The austenite grain size ranged from $0.031 \mathrm{~mm}$ to $0.088 \mathrm{~mm}$, with hardness ranging from 156 to $212 \mathrm{HV} \mathrm{5}$. It is shown that the use of the $12 \mathrm{Cr} 15 \mathrm{Mn} 9 \mathrm{NiCu}$ corrosion-resistant chromium-nickelmanganese steel intended for the manufacture of heat exchangers for metallurgical production is extremely inappropriate.

Keywords: corrosion-resistant steel, oxides, sulfides, microstructure, austenite, martensite, hardness.

\section{Acknowledgments}

The research used the facilities of the Plastometriya shared access center at the IES UB RAS. It was performed according to the state assignment on theme No. AAAA-A18-118020790145-0.

We appreciate the effort of E. B. Trushina, who assisted us in the research. 


\section{References}

1. Ulyanin E.A. Korrozionnostoykie stali i splavi: Spravochnik [Corrosion-resistant Steels and Alloys: A Handbook]. Moscow: Metallurgiya Publ., 1991, 255 p. ISBN: 5-229-00808-3. (In Russian).

2. Tufanov D.G., Korrozionnaya stoikost nerzhaveyushchikh stalei, splavov $i$ chistykh metallov: Spravochnik [Corrosion Resistance of Stainless Steels, Alloys, and Pure Metals: A Handbook]. Moscow, Metallurgiya Publ., 1990, 320 p. ISBN: 5-229-00531-9. (In Russian).

3. Babakov A.A., Pridantsev M.V. Korrozionnostoykie stali i splavy [Corrosion-resistant steels and alloys]. Moscow, Metallurgiya Publ., 1971, 318 p. (In Russian).

4. Shlyamnev A.P., Svistunova T.V., Lapina O.B., Sorokona N.A., Matorin V.I., Stolyarov V.I., Bogolyubskiy S.D., Kozlova N.N., Enderal A.F. Korrozionnostoykie, zharostoykie i vysokoprochnye stali i splavy [Corrosion-Resistant, Heat-Resistant and High-Strength Steels and Alloys: A Reference Book]. Moscow, Intermet Engineering Publ., 2000, 232 p. ISBN: 5-89594-028-5. (In Russian).

5. Ki Leuk Lai J., Kin Ho Lo, Chan Hung Shek, eds. Stainless Steels: An Introduction and their Recent Developmentsm, Bentham Science Publishers, 2012, 168 p. DOI: 10.2174/97816080530561120101.

6. Brooks J.A. Weldability of high N, high Mn austenitic stainless steel. Welding Research Supplement, 1975, no. 6, pp. 189-195.

7. Uggowitzer P.J., Magdowski R., Speidel M.O. Nickel Free High Nitrogen Austenitic Steels. ISIJ International, 1996, vol. 36, no. 7, pp. 901-908. DOI: 10.2355/isijinternational.36.901.

8. Goldshtein M.I., Grachev S.V., Veksler Yu.G. Spetsialnye stali [Special steels]. Moscow, MISIS Publ., 1999, 408 p. ISBN: 5-87623-032-4. (In Russian).

9. $\quad$ Robino C.V., Michael J.R., Maguire M.C. The solidification and weld metallurgy of galling resistant stainless steels. Welding Journal, 1998, vol. 77, no. 11, pp. 446-457.

10. Tehovnik F., Vodopivec F., Kosec L., Godec M. Hot ductility of austenite stainless steel with a solidification structure. Materiali in Tehnologije, 2006, vol. 40, pp. 129-137.

11. Sung J.H., Joo D.W., Kim I.S., Kang C.Y., Sung J.H. Phase changes of Fe-20Mn-13 Cr-3Co/1.2Ti alloys during solution nitriding. Met. Mater. Int., 2005, vol. 11, pp. 157-163. DOI: $10.1007 / \mathrm{BF} 03027460$.

12. Williamson D.L., Davis J.A., Wilbur P.J. Effect of austenitic stainless steel composition on low-energy, high-flux, nitrogen ion beam processing. Surf. Coat. Technol., 1998, vol. 103-104, pp. 178-184. DOI: 10.1016/s0257-8972(98)00389-2.

13. Samandi M., Shedden B.A., Smith D.I., Collins G.A., Hutching R., Tendys J. Microstructure, corrosion and tribological behaviour of plasma immersion ion-implanted austenitic stainless steel. Surf. Coat. Technol., 1993, vol. 59, pp. 261-266. DOI: 10.1016/0257-8972(93)90094-5.

14. Mändl S., Manova D., Neumann H., Pham M.T., Richter E., Rauschenbach B. Correlation between PIII nitriding parameters and corrosion behavior of austenitic stainless steels. Surface \& Coatings Technology, 2005, vol. 200, pp. 104-108. DOI:10.1016/J.SURFCOAT.2005.02.084.

15. Hansen M., Anderko K. Constitution of binary alloys, McGraw Hill Book Co., Inc., New York/Toronto, 1958, pp. 670-675.

16. A.G. Rakhstadt and V.V. Bromtrem, eds. Spravochnik metallista [Metalworker's Guide, in 5 volumes. Vol. 2]. Moscow, 1976, 720 p. (In Russian).

17. Materialy v mashinostroenii. Vybor i primenenie, ed. I.V. Kudryavtseva [Materials in mechanical engineering. Selection and application: reference book in five volumes. Vol. 3. Special steels and alloys, ed. F.F. Himushina]. Moscow, Mashinostroenie Publ., 1968, 217 p. (In Russian).

18. Stali i splavy. Marochnik: sprav. izd. [Steels and Alloys: Grade Guide, eds. V.G. Sorokin, M.A. Gervasiev]. M., Intermet Inzhiniring Publ., 2003, 608 p. (In Russian).

19. Sung J.H., Joo D.W., Kim I.S., Kang Chang Yong \& Sung Jang Hyun. Phase changes of $\mathrm{Fe}-20 \mathrm{Mn}-13 \mathrm{Cr}-3 \mathrm{Co} / 1.2 \mathrm{Ti}$ alloys during solution nitriding. Met. Mater. Int., 2005, vol. 11, pp. 157-163. DOI: 10.1007/BF03027460. 
20. Klyuch staley. Izgotovlenie i postavka: spravochnik [Key to Steels. Production and Delivery: reference book, trans. Germ.]. M., Intermet Inzhiniring Publ., 2001, 734 p. (In Russian).

21. Ning Liu, Zhonggang Deng, Menggen Huang. Effect of heat treatment on microstructure and mechanical properties of martensitic-ferritic stainless steel containing $17 \% \mathrm{Cr}$ and $2 \% \mathrm{Ni}$. Materials Science and Technology, 1991, vol. 7, pp. 1057-1062. DOI: 10.1179/mst.1991.7.11.1057.

22. Metallographiya zheleza [Metallography of Iron, ed. F.N. Tavadze, transl. Engl. by Z.Sh. Kherodinashvili, L.P. Danilenko. Vol. 3. Crystallization and deformation of steels]. Moscow, Metallurgiya Publ., 1972. (In Russian).

23. Engel' L. and Klingele G. Rastrovaya elektronnaya microskopiya. Razrushenie [Scanning Electron Microscopy. Fracture: A Handbook, Germ. transl.]. Metallurgiya, Moscow, 1986. (In Russian). 
Подана в журнал: 08.04.2021

УДК 669.017.16

DOI: $10.17804 / 2410-9908.2021 .3 .017-030$

\title{
ИССЛЕДОВАНИЕ ХИМИЧЕСКОГО И ФАЗОВОГО СОСТАВОВ ХРОМОНИКЕЛЬМАРГАНЦЕВОЙ СТАЛИ ПОСЛЕ ЭКСПЛУАТАЦИИ В АГРЕССИВНЫХ СРЕДАХ ПРИ ПОВЫШЕННЫХ ТЕМПЕРАТУРАХ
}

\author{
Н. Б. Пугачева ${ }^{1, \text { a)* }}$, Б. Н. Гузанов ${ }^{2, \text { в) }}$ \\ ${ }^{1}$ Институт машиноведения УрО РАН, \\ д. 34, ул. Комсомольская, г. Екатеринбург, 620049, Российская Федераџия \\ ${ }^{2}$ Российский государственный профессионально-педагогический университет, \\ д. 11, ул. Машиностроителей, г. Екатеринбург, 620012, Российская Федерация \\ a) (D) http://orcid.org/0000-0001-8015-8120 @ nat@imach.uran.ru; \\ b) (ID http://orcid.org/0000-0001-5698-0018 @ guzanov_bn@mail.ru \\ *Ответственный автор. Электронная почта: nat@imach.uran.ru \\ Адрес для переписки: ул. Комсомольская, 34, г. Екатеринбург, Российская Федерация \\ Тел.: +7 (343) 362-30-43; факс: +7 (343) 374-53-30
}

В последние годы широко применяют хромоникельмарганцевые коррозионностойкие стали в строительстве для изготовления лестничных перил и ограждений, лифтов, теплообменников, используемых для утилизации тепла в офисных помещениях и на производстве, в том числе и в металлургических цехах. Цель работы - определение изменений химического и фазового составов коррозионностойкой стали марки 12Х15Г9НД (Российский аналог стали AISI 201) после промышленной эксплуатации в элементах конструкции теплообменника металлургического цеха. Установлено, что все исследованные фрагменты теплообменника из стали 12 Х15Г2НД при эксплуатации подверглись интенсивному окислению с образованием оксидов хрома и марганца как на поверхности, так и по границам аустенитного зерна. Зафиксировано диффузионное проникновение серы в сталь с образованием частиц $\mathrm{MnS}$, а также науглероживание поверхностных слоев. В результате значительно снизилось содержание хрома и марганца в стали, увеличилось количество углерода, структура изменилась от аустенитной до мартенситной с твердостью 532 HV 5 (48 HRC). В нескольких исследованных фрагментах сохранился аустенит с окисленными границами зерен. Размер аустенитного зерна колебался от 0,031 до 0,088 мм, твердость - от 156 до 212 HV 5. Показано, что использование хромоникельмарганцевой коррозионностойкой стали $12 \mathrm{X} 15$ ГАНД для изготовления теплообменников металлургического производства крайне нецелесообразно.

Ключевые слова: коррозионностойкая сталь, оксиды, сульфиды, микроструктура, аустенит, мартенсит, твердость.

\section{1. Введение}

Стойкость сталей и сплавов к химической или электрохимической коррозии (атмосферной, почвенной, щелочной, кислотной, солевой), межкристаллитной коррозии и коррозии под напряжением определяется прежде всего их химическим составом [1-5]. Основным принципом легирования коррозионностойких сталей является обеспечение перехода стали в пассивное состояние. Легко пассивирующимися металлами являются алюминий, хром, никель, титан [1-3]. На поверхности этих металлов на воздухе образуется защитная окисная пленка, которая защищает их от коррозионного воздействия атмосферы, воды, агрессивных сред. Максимальными защитными свойствами обладает оксид алюминия $\mathrm{Al}_{2} \mathrm{O}_{3}$, однако повышать концентрацию алюминия в стали нецелесообразно, поскольку при этом снижаются 
технологические свойства, такие как обрабатываемость давлением (ковка, прокатка, прессование). Основным легирующим элементом коррозионностойких сталей является хром, содержание которого обычно находится в интервале от 11 до 30 мас. \% [1, 2; 6-8]. Верхний предел концентрации хрома ограничивается образованием охрупчивающей б-фазы, поэтому в аустенитных сталях рекомендовано не повышать содержание этого элемента выше 22 мас. \% [8].

Никель не только повышает коррозионную стойкость, но главным образом, стабилизирует аустенитную структуру стали, обеспечивающую высокую технологическую пластичность при операциях горячей и холодной деформации и хладостойкость при криогенных температурах. К стабилизирующим аустенитную структуру элементам относятся углерод, азот и медь, однако вследствие ограниченной растворимости в кристаллической решетке железа эти элементы могут образовывать избыточные фазы (карбиды, нитриды и интерметаллиды), поэтому их вводят в сталь в весьма ограниченном количестве [6-8]. Медь в небольших количествах способствует улучшению свариваемости коррозионностойких сталей [9].

Титан и ниобий вводят в коррозионностойкие стали для связывания углерода в карбиды $\mathrm{TiC}$ и $\mathrm{NbC}$. При этом уменьшается вероятность образования карбидов хрома по границам зерен и обеднение приграничных участков по хрому. Таким образом, предотвращается межкристаллитная коррозия, которая особенно опасна в сварных конструкциях $[1,7]$. Для снижения опасности возникновения межкристаллитной коррозии целесообразно снижать содержание углерода в коррозионностойких сталях, чтобы исключить образование карбидов хрома по границам зерен. Молибден в количествах от 2 до 4 мас. \% также способствует повышению коррозионной стойкости по такому же механизму, что титан и ниобий. Однако повышение его содержания нежелательно, поскольку приводит к появлению феррита в структуре стали $[1,2,8]$. Кремний вводят в очень небольших количествах, как правило, не более 1 мас. \%, для повышения защитных свойств оксидной пленки на поверхности стали. При более высоких содержаниях кремний способствует появлению феррита в структуре стали, а также может образовывать силициды хрома, что снижает коррозионную стойкость [8].

Марганец на воздухе образует окисную пленку, но ее нельзя считать защитной, поскольку она быстро разрушается даже при незначительном повышении температуры и в присутствии серы или других активных реагентов, например хлора. В сталях марганец может входить в состав цементита $(\mathrm{Fe}, \mathrm{Mn})_{3} \mathrm{C}$, образовывать самостоятельные карбиды, которые повышают твердость и износостойкость, образует сульфиды, фосфиды, бориды, нитриды и другие неметаллические включения. Его вводят в состав коррозионностойких сталей, главным образом для замены дорогостоящего никеля в качестве элемента, стабилизирующего аустенитную структуру. При этом необходимо строго сбалансировать содержание хрома и никеля и ввести азот, поскольку в противном случае существует опасность снижения коррозионной стойкости или появления в структуре стали ферритной составляющей $[5,8,10]$. Именно поэтому в Российских стандартах присутствуют стали марок 10Х14Г14Н3; 10Х14Г14Н4Т; 10Х14АГ15; 15Х17АГ14; 12Х17Г9АН4; 07Х21Г7АН5 [10-13], в которых для обеспечения сочетания высокой коррозионной стойкости и сохранения однофазной аустенитной структуры содержание хрома составляет не менее 14 мас. \% при одновременном введении марганца и/или азота.

В справочной литературе [1, 2; 11-13] отмечается, что хромомарганцевоникелевые и безникелевые стали аустенитного класса существенно проигрывают хромоникелевым сталям по коррозионной стойкости. Поэтому они применяются для изготовления бытовых приборов, торгового и пищевого оборудования, пассажирских вагонов, барабанов стиральных машин и др., где температуры их использования не превышают $300{ }^{\circ} \mathrm{C}$ [10-12]. Однако в последнее время намечается тенденция расширения области применения сталей группы 200 по стандарту AISI, в частности стали марки 201. Причиной этого является ряд преимуществ сталей этого класса: хорошая свариваемость, пластичность при деформации, например в условиях 
глубокой вытяжки, отличная полируемость до зеркального блеска, отсутствие порога хладноломкости, что позволяет использовать изделия при низких температурах (в криогенной технике) [1-5]. В последние годы стали группы 200 чаще рекомендуют к применению для деталей, эксплуатируемых при более высоких температурах. Например, сталь марки AISI 201 применяют для изготовления элементов конструкций теплообменников, используемых для утилизации тепла в офисных помещениях и на производстве, в том числе в металлургических цехах. В последнем случае кроме достаточно высоких температур (600-900 $\left.{ }^{\circ} \mathrm{C}\right)$ на конструкцию теплообменника воздействует воздушная атмосфера, в которой содержатся такие агрессивные химические соединения, как углекислый газ $\mathrm{CO}_{2}$ и окись углерода $\mathrm{CO}$ (угарный газ), двуокись серы $\mathrm{SO}_{2}$ (сернистый газ) и трехокись серы $\mathrm{SO}_{2}, \mathrm{SO}_{3}$ (серный газ), пары воды, кислород. Из Российских аналогов наиболее близки по химическому составу стали AISI 201 марки 12X17Г9АН4, с более высоким содержанием азота (0,30-0,45 мас. \%) и 12Х15Г9НД с содержанием азота до 0,2 мас. \% и меди до 2,0 мас. \%. К сталям этой группы относятся также стали марок AISI 202 (Российский аналог 12X17Г9ФН4), AISI 203 E2 с меньшим содержанием углерода, марганца и молибдена ( $\leq$ 0,5 мас. \%), AISI 205 с повышенным содержанием азота (до 0,45 мас. \%).

Цель исследования - установить изменения химического и фазового составов хромомарганцевой коррозионностойкой стали марки 12Х15Г9НД (Российский аналог стали AISI 201) после промышленной эксплуатации в элементах конструкции пластинчатого теплообменника.

\section{2. Материалы и методы исследования}

Исследовали фрагменты коллектора газохода, диффузора дыма и гофрированного корпуса пластинчатого теплообменника после эксплуатации в условиях металлургического производства. Выбранные элементы конструкции теплообменника изготовлены из хромомарганцевой коррозионностойкой стали марки $12 \mathrm{X} 15 Г 9 Н Д$, являющейся Российским аналогом стали AISI 201. Теплообменник использовался без подогрева природным газом. Состав отходящих газов, об. \%: 1) при штатном режиме работы шахтной печи - 0,1-0,16 $\mathrm{SO}_{2} ; 0,02 \mathrm{SO}_{3}$; 0,6-5,0 CO; $3,0-5,0 \mathrm{CO}_{2} ; 10,0-18,6 \mathrm{O}_{2} ; 3,8-4,3 \mathrm{H}_{2} \mathrm{O} ; \mathrm{N}_{2}$ - остальное; 2) при пуске печи 0,1-0,16 $\mathrm{SO}_{2}$; 0,2 $\mathrm{SO}_{3}$; до 10,0 CO; до 20,0 $\mathrm{CO}_{2} ; 3,0-16,0 \mathrm{O}_{2} ; 3,8-4,3 \mathrm{H}_{2} \mathrm{O} ; \mathrm{N}_{2}$ - остальное. Средняя температура дымовых газов составляла $600{ }^{\circ} \mathrm{C}$, кратковременная (длительностью до 2 ч - 700-900 ${ }^{\circ} \mathrm{C}$ ). В связи с технологическими особенностями эксплуатации теплообменника, температура дымовых газов отличается существенными колебаниями в указанном диапазоне. Запыленность

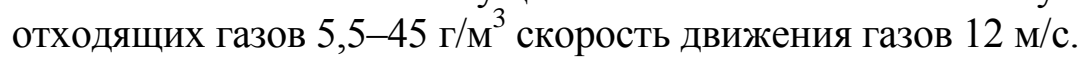

Химический состав стали исследованных фрагментов теплообменника определяли методом эмиссионной спектроскопии на приборе SPECTROMAXх. Микроструктуру и химический состав неметаллических включений и окисных пленок на поверхности фрагментов исследовали на растровом электронном микроскопе TESCAN VEGA II XMU с энергодисперсионной приставкой INCA ENERGY 450 с ADD детектором OXFORD. Микроструктуру стали исследовали методами оптической (NEOPHOT 21) и растровой электронной микроскопии (микроскоп TESCAN VEGA II XMU). Идентификацию микроструктуры проводили по ГОСТ 8233 - 56. Размер аустенитного зерна определяли методом сравнения с эталонными шкалами по ГОСТ 5639-82. Твердость по Виккерсу измеряли на твердомере AKASHI при нагрузке 49 Н в соответствии с требованиями ГОСТ Р ИСО 6507-1 - 2007.

\section{3. Результаты и их обсуждение}

Исследованные фрагменты теплообменника представляли собой пластины толщиной 3-5 мм с шероховатой и сильно окисленной поверхностью (рис. $1 a$ ). В материале фрагмента 1 обнаружены флокены - дефекты в виде разрывов стали под влиянием растворенного в стали водорода и внутренних напряжений (рис. 1 б). Флокены обычно диагностируют по излому отливки (ГОСТ 10243 - 75), на котором они представлены в виде пятен круглой или овальной 
формы с кристаллической поверхностью. На поперечных резах исследованного фрагмента коллектора газохода наблюдали пустоты овальной формы (рис. $16 ; 2 a$ ), появление которых обусловлено проникновением водорода в сталь при забросе рабочих температур теплообменника до 700-900 ${ }^{\circ} \mathrm{C}$. Растрескивание стали в виде дефекта «вороньей ноги» (рис. 2 б) также является признаком наводороживания стали [14].

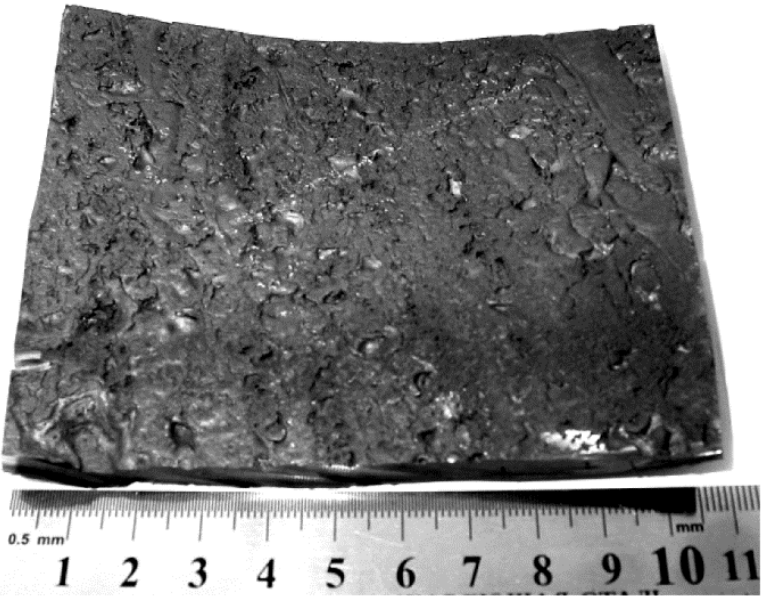

$a$

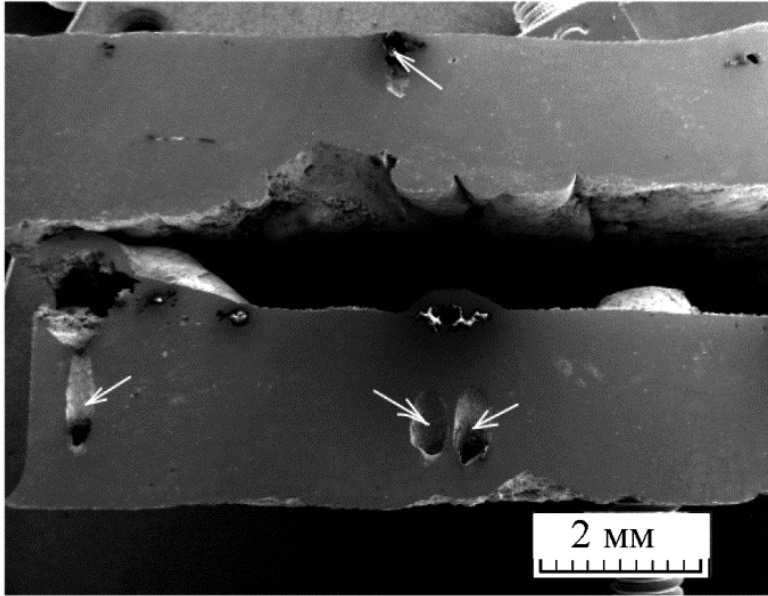

$\sigma$

Рис. 1. Внешний вид $(a)$ и внутренние повреждения (б) коллектора газохода теплообменника из стали $12 \mathrm{X} 15$ ГОНД после эксплуатации: $a$ - окисленная поверхность с питтингами; $\sigma$ - флокены на поперечном резе отмечены стрелками (изображение во вторичных электронах)

Таблица 1 - Химический состав стали исследованных фрагментов теплообменника, мас. \%

\begin{tabular}{|c|c|c|c|c|c|c|}
\hline \multirow{2}{*}{$\begin{array}{c}\text { № фраг- } \\
\text { мента }\end{array}$} & \multirow{2}{*}{$\begin{array}{c}\text { Наименование } \\
\text { детали }\end{array}$} & \multicolumn{5}{|c|}{ Химические элементы, мас. \% } \\
\hline & & $\mathrm{C}$ & $\mathrm{Cr}$ & $\mathrm{Mn}$ & $\mathrm{Ni}$ & $\mathrm{Cu}$ \\
\hline 1 & $\begin{array}{c}\text { Коллектор } \\
\text { газохода }\end{array}$ & 0,4 & 8,7 & 1,9 & 1,3 & 2,0 \\
\hline 2 & Диффузор дыма & 0,12 & 14,0 & 8,6 & 1,0 & 1,9 \\
\hline 3 & Панель 1 & 0,12 & 13,7 & 5,8 & 0,9 & 1,9 \\
\hline 4 & Панель 2 & 0,10 & 14,5 & 8,9 & 1,1 & 1,8 \\
\hline \multicolumn{2}{|c|}{ Исходная сталь } & 0,08 & 14,8 & 8,6 & 1,0 & 1,5 \\
\hline \multicolumn{7}{|c|}{ Fe - остальное } \\
\hline
\end{tabular}

По данным спектрального химического анализа, в материале фрагмента коллектора газохода содержание хрома уменьшилось в 1,7 раза, а марганца - в 4,5 раза, количество углерода увеличилось до 0,4 мас. \%. (в табл. 1; № 1). Микрорентгеноспектральный анализ поверхности поперечных шлифов показал, что вблизи боковой поверхности произошло интенсивное окисление стали с образованием оксидов хрома и марганца (рис. 2 a). Сера из газовой среды теплообменника при высокой температуре легко диффундировала в сталь, провзаимодействовала с марганцем с образованием множественных частиц сульфида марганца (рис. 2 в, г; табл. 2). Вследствие этого содержание марганца и хрома в стали существенно снизилось. Изменение химического состава привело к изменению структуры с аустенитной на мартенситную. Микроструктура материала фрагмента коллектора газохода соответствует среднеигольчатому мартенситу с максимальной длиной игл 10 мкм (рис. $3 a$ ). Твердость стали этого фрагмента составила 532 HV5 или 48-49 HRC, что соответствует закаленному состоянию. Известно, что аустенитные коррозионностойкие стали марок 
12Х15Г9НД или 12Х17Г9АН4 при любых термических обработках сохраняют аустенитную структуру и не претерпевают мартенситного превращения $[3,5]$. Очевидно, при эксплуатации теплообменника произошло существенное изменение химического состава стали, что привело к изменению структуры.

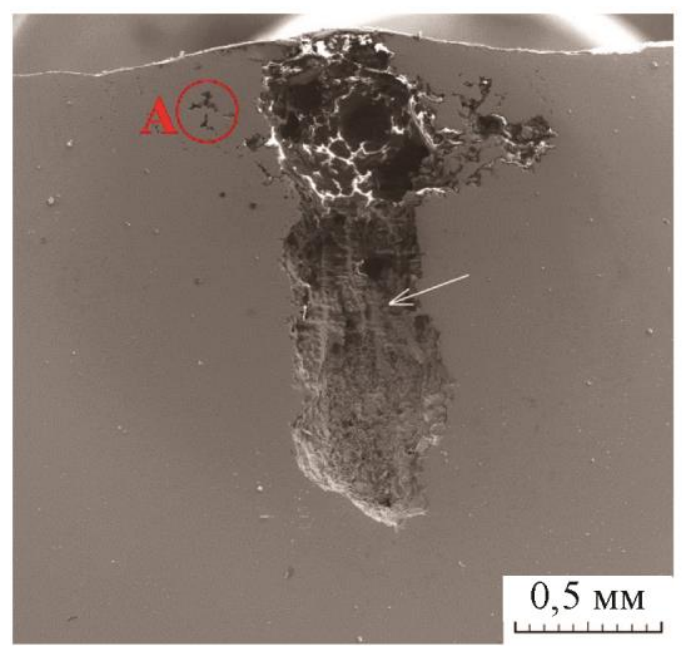

$a$

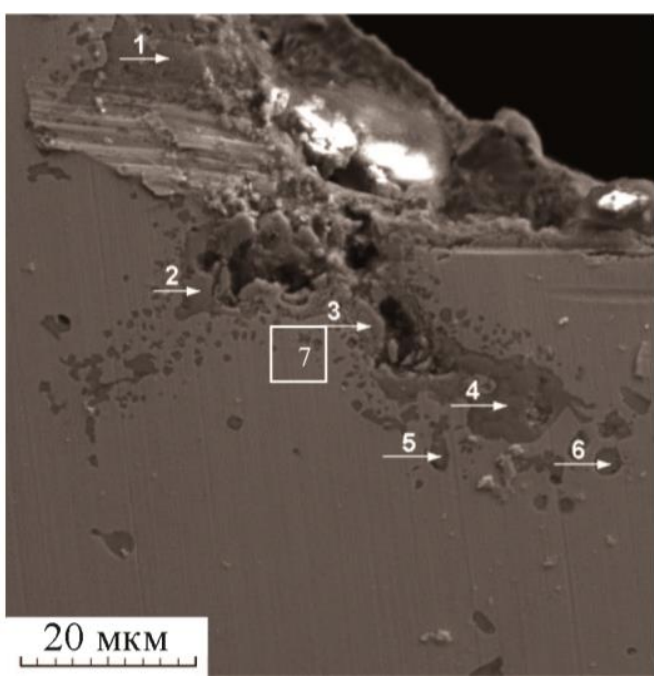

B

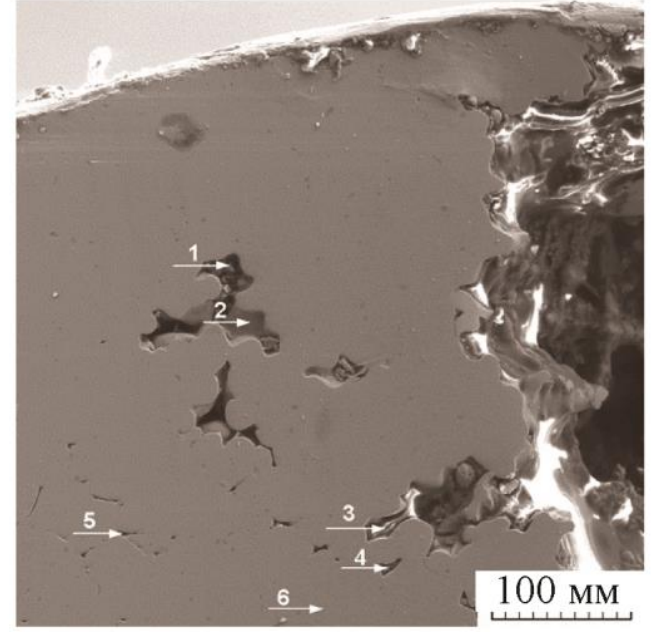

$\sigma$

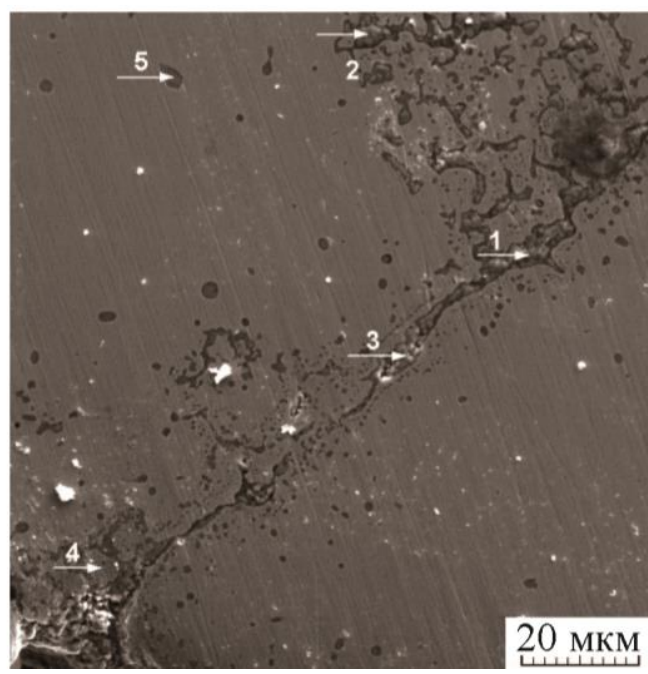

2

Рис. 2. Повреждения коллектора газохода теплообменника из стали 12 Х15Г9НД после эксплуатации: $a$ - флокен (отмечен стрелкой); $\sigma$ - разрывы в виде «вороньей ноги» (рис. $a$; участок А); в - окисление поверхности; 2 - сквозное повреждение (оксиды и сульфиды)

На внутренней поверхности фрагмента диффузора дыма наблюдали слой оксидов (фрагмент 2 в табл. 1). Анализ химического состава различных участков поверхности поперечных резов показал наличие оксидов $\mathrm{Cr}, \mathrm{Mn}, \mathrm{Si}, \mathrm{Fe}, \mathrm{Cu}$ и $\mathrm{Ni}$ на внутренней поверхности и сульфидов $\mathrm{MnS}$ в стали вблизи поверхности (рис. 4; табл. 3). Зафиксировано присутствие углерода на внутренней поверхности фрагмента диффузора дыма в виде налета и даже проникновение частиц углерода в сталь на глубину 10 мкм (точка 12 на рис. 4 б). На участках вблизи поверхности сталь также, как на фрагменте коллектора газохода, существенно изменила состав: заметно уменьшилось содержание хрома и марганца (точки 11 на рис. 46 и 1 на рис. 4 в; табл. 3). Твердость стали фрагмента составила 216 HV 5. Микроструктура фрагмента со- 
ответствует аустениту с размером зерна от 0,031 мм (7-й балл по ГОСТ 5639-82) до 0,088 мм (4-й балл по ГОСТ 5639-82) (рис. 3 г). Материал фрагмента содержит повышенное количество оксидов точечных, которые образовались при окислении стали в процессе эксплуатации. Аустенитные стали не склонны к росту зерна при нагревах, в исходном состоянии обычно они мелкозернисты - аустенитное зерно соответствует 12-14-му баллу ГОСТ 563982 со средним диаметром 0,0027-0,0056 мм. Увеличение размера зерна стали до 4-го балла свидетельствует о кратковременном повышении (не более 1 ч) температуры до 1100-1300 ${ }^{\circ} \mathrm{C}$.

Таблица 2 - Химический состав участков

\begin{tabular}{|c|c|c|c|c|c|c|c|c|c|}
\hline \multirow{2}{*}{$\begin{array}{c}\text { № } \\
\text { П. П. }\end{array}$} & \multicolumn{9}{|c|}{ Химические элементы, мас. \% (основа - Fе) } \\
\hline & $\mathrm{C}$ & $\mathrm{Cr}$ & $\mathrm{Mn}$ & $\mathrm{Ni}$ & $\mathrm{Cu}$ & $\mathrm{S}$ & $\mathrm{O}$ & $\mathrm{Si}$ & Примечание \\
\hline \multicolumn{10}{|c|}{ Участки анализа (рис. 2 б) } \\
\hline 1 & 1,9 & 16,3 & 3,8 & 0 & 1,1 & 0 & 23,7 & 0 & \multirow{2}{*}{$\begin{array}{c}\text { Оксиды хрома } \\
\text { и марганца } \\
\end{array}$} \\
\hline 2 & 1,5 & 8,3 & 1,7 & 1,0 & 0 & 0 & 25,1 & 0 & \\
\hline 3 & 0 & 34,2 & 11,2 & 0 & 0,7 & 6,5 & 24,5 & 1,3 & $\mathrm{Cr}_{2} \mathrm{O}_{3}, \mathrm{MnS}$ \\
\hline 4 & 1,9 & 20,3 & 2,4 & 1,5 & 1,0 & 0 & 23,2 & 0,3 & \multirow{2}{*}{$\begin{array}{c}\text { Оксиды хрома и } \\
\text { марганца, углерод }\end{array}$} \\
\hline 5 & 1,8 & 41,5 & 21,0 & 0 & 0 & 0 & 24,5 & 0,3 & \\
\hline 6 & 0,12 & 9,7 & 2,1 & 1,6 & 2 & 0 & 0 & 0 & Сталь \\
\hline \multicolumn{10}{|c|}{ Участки анализа (рис. 2 в) } \\
\hline 1 & 11,1 & 8,2 & 2,0 & 0,7 & 0,2 & 0 & 12,8 & 0 & $\begin{array}{c}\text { Углерод, } \mathrm{Cr}_{2} \mathrm{O}_{3}, \\
\mathrm{MnO},\end{array}$ \\
\hline 2 & 43,8 & 3,2 & 0,6 & 0,4 & 0 & 0,1 & 18,5 & 0,1 & $\begin{array}{c}\text { Углерод, } \mathrm{MnS}, \\
\mathrm{Cr}_{2} \mathrm{O}_{3}\end{array}$ \\
\hline 3 & 4,8 & 9,11 & 1,83 & 0,2 & 1,36 & 0 & 22,3 & 0 & \multirow{4}{*}{$\begin{array}{c}\text { Оксиды хрома } \\
\text { и марганца, } \\
\text { углерод }\end{array}$} \\
\hline 4 & 1,7 & 25,4 & 16,5 & 0 & 0 & 0 & 26,4 & 0 & \\
\hline 5 & 10,5 & 8,66 & 1,98 & 1,42 & 1,38 & 0 & 24,0 & 0 & \\
\hline 6 & 1,5 & 28,3 & 17,5 & 0 & 0 & 0 & 25,8 & 0 & \\
\hline 7 & 0,5 & 9,5 & 1,8 & 1,4 & 1,5 & 0 & 0 & 0,1 & Сталь \\
\hline \multicolumn{10}{|c|}{ Участки анализа (рис. 2 г) } \\
\hline 1 & 26,3 & 11,6 & 1,44 & 4,25 & 0 & 0,12 & 13,8 & 0,15 & $\begin{array}{c}\text { Углерод, } \mathrm{FeO}, \\
\mathrm{SiO}_{2}\end{array}$ \\
\hline 2 & 14,7 & 8,68 & 1,85 & 0,82 & 0,32 & 0,14 & 18,7 & 0,34 & \multirow{4}{*}{$\begin{array}{c}\text { Углерод, } \mathrm{FeO}, \\
\mathrm{SiO}_{2}, \mathrm{SO}_{2}\end{array}$} \\
\hline 3 & 70,9 & 1,63 & 0,44 & 0 & 0 & 0,26 & 14,8 & 0 & \\
\hline 4 & 39,8 & 6,02 & 2,01 & 0,91 & 0,24 & 0,15 & 16,1 & 0 & \\
\hline 5 & 15,9 & 9,23 & 1,78 & 1,24 & 1,38 & 0,24 & 19,2 & 0,12 & \\
\hline 6 & 0,15 & 8,62 & 1,82 & 1,54 & 1,44 & 0 & 0 & 0 & Сталь \\
\hline
\end{tabular}

Для фрагментов 3 и 4 (табл. 1) наружного кожуха теплообменника характерно поверхностное окисление (рис. 4 в, г). Глубина окисленного слоя на фрагменте 4 больше, чем у фрагмента 3: 0,6 и 1,0 мм соответственно. Твердость составила 195 HV 5 для фрагмента 3 и 156 HV 5 для фрагмента 4. Для фрагмента 3 как и для фрагмента 2, характерна разнозернистость аустенита от 3 до 7 баллов по ГОСТ 5639-82 (рис. 3 в). Фрагмент 4 характеризуется преимущественно крупным аустенитным зерном 3-4 балла по 5639-82 с размерами от 0,088 мм до 0,125 мм (рис. 3 г). Очевидно фрагмент 4 испытывал воздействие высоких температур более длительное время, в нем кроме чрезмерного увеличения аустенитного зерна наблюдали пережог, сопровождающийся окислением границ зерен с образованием оксидов хрома 
и марганца. В результате по границам зерен образуются пустоты, заполненные оксидами (рис. 3 2), а сталь вблизи границ существенно обеднена по хрому и марганцу. Низкая твердость материала фрагмента 4 обусловлена пережогом стали.

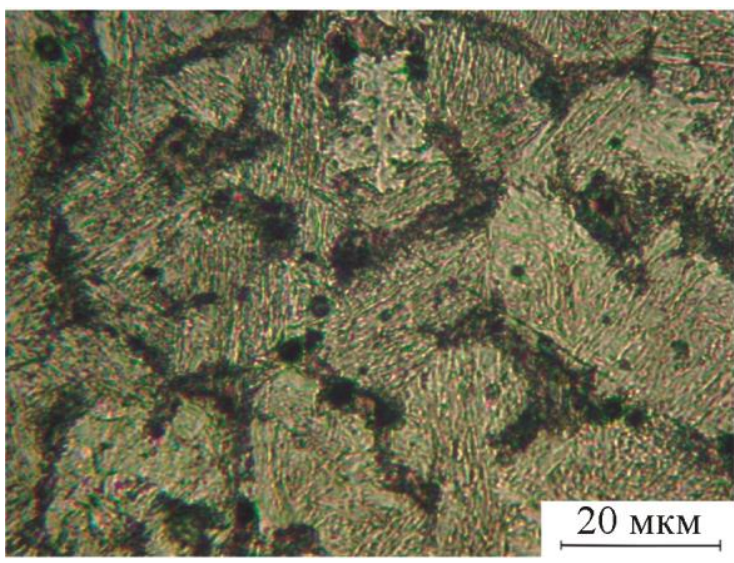

$a$

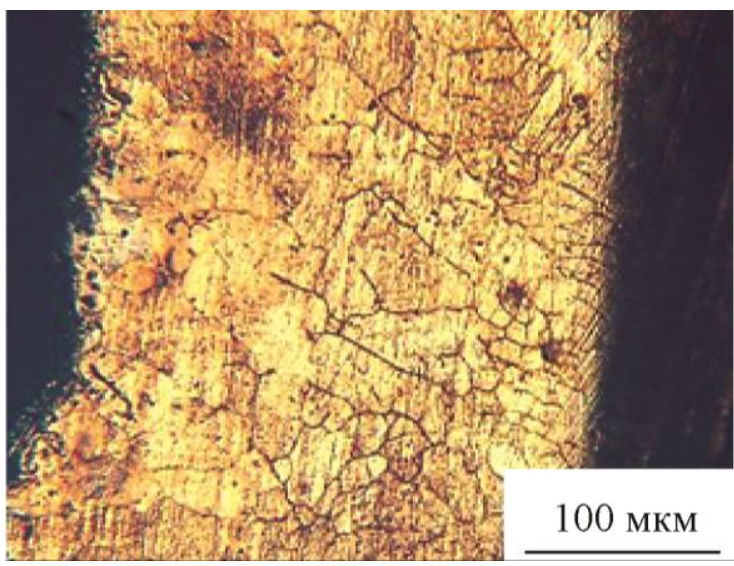

B

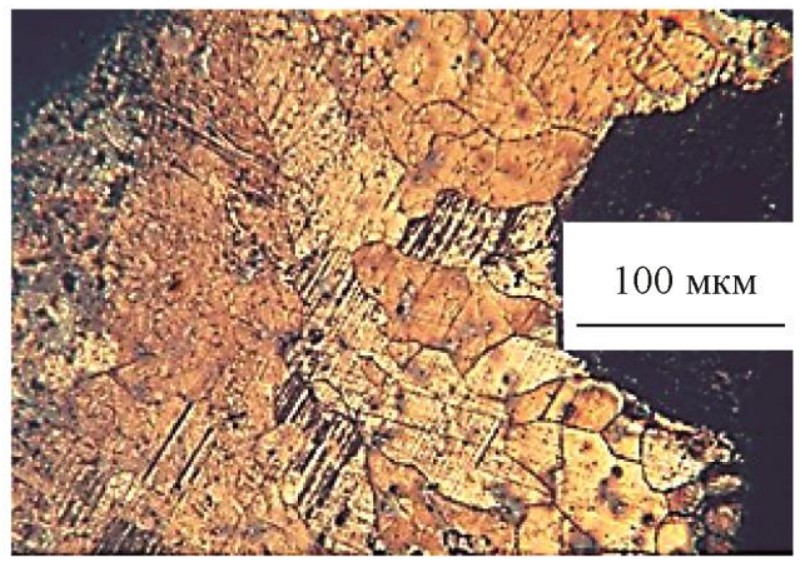

б

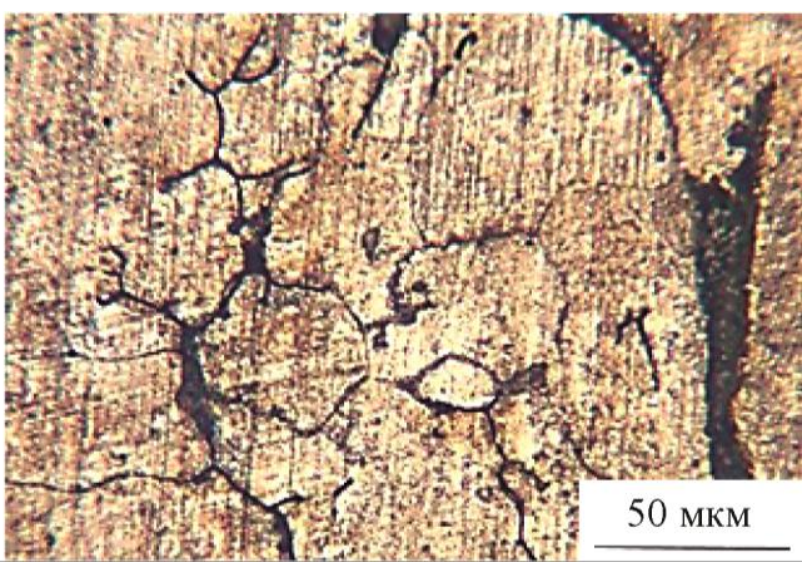

2

Рис. 3. Микроструктура исследованных фрагментов теплообменника из стали 12 Х15Г9НД после эксплуатации: $a$ - мартенсит и окисленные границы зерен в коллекторе газохода; $\sigma$ - крупные аустенитные зерна в диффузоре дыма; в - панель; 2 - сквозное повреждение панели (оксиды и сульфиды расположены по границам аустенитных зерен)

Полученные результаты показали, что при выборе материала для изготовления теплообменника следует исходить из условий его эксплуатации. В металлургическом производстве теплообменник (рекуператор) обычно устанавливается в газоход отходящих газов плавильных печей. Поэтому невозможно избежать интенсивного окисления и диффузии серы в сталь, а также науглероживания. Основные требования при выборе марки стали для изготовления пластинчатых оребренных рекуператоров:

1) повышенная коррозионная стойкость в интервале температур от 20 до $1000{ }^{\circ} \mathrm{C}$;

2) хорошая свариваемость и отсутствие склонности к межкристаллитной коррозии в районе сварных швов;

3) эрозионная стойкость поверхности в условиях воздействия скоростного газового потока с частицами пыли.

Учитывая данные Российских справочников по применению коррозионностойких сталей $[7,8]$, для условий работы рекуператора следует выбрать хромоникелевую сталь аустенитного класса марки 08Х18Н10Т или хромоникельмарганцевую сталь марки 10Х14Г14Н4Т (ЭИ711). 
При этом следует отметить, что сталь марки 08Х18Н10Т выгодно отличается более высокой стойкостью сварных соединений против ножевой и межкристаллитной коррозии, особенно на участках сварных соединений [4].

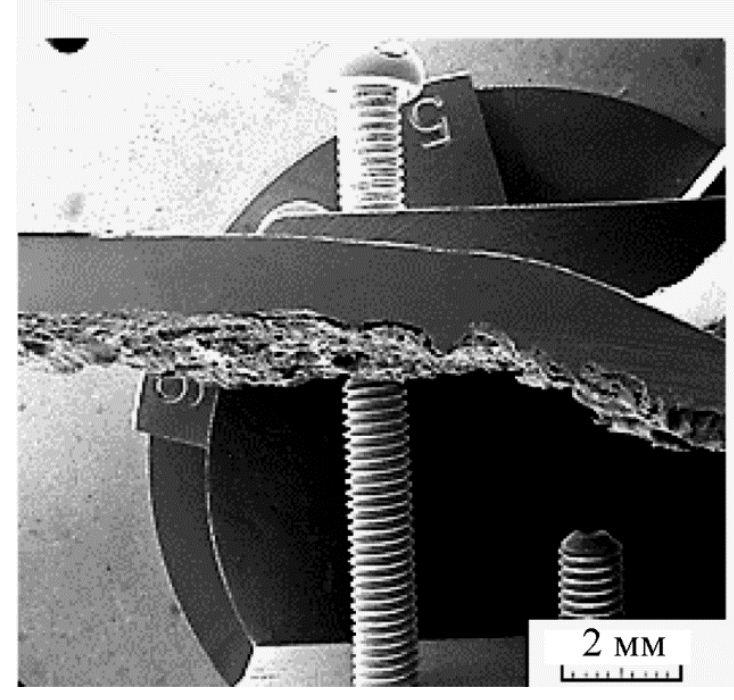

$a$

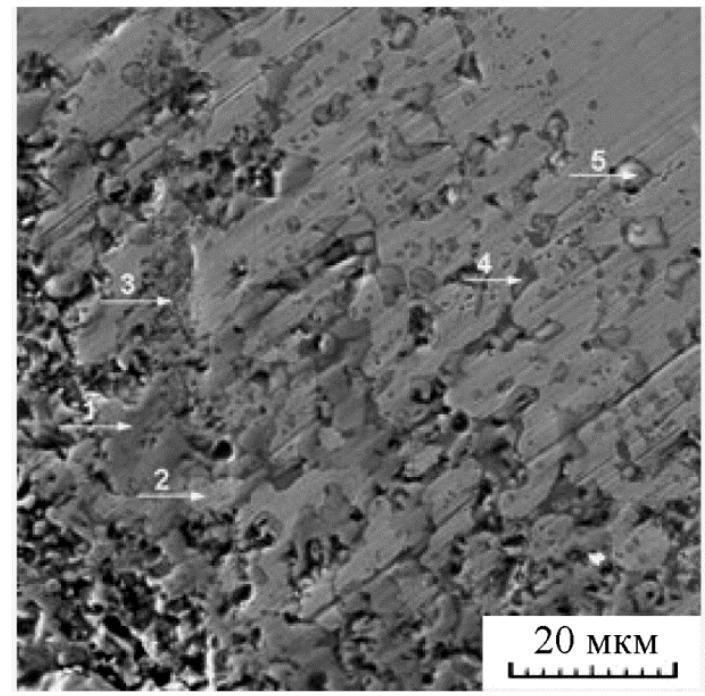

B

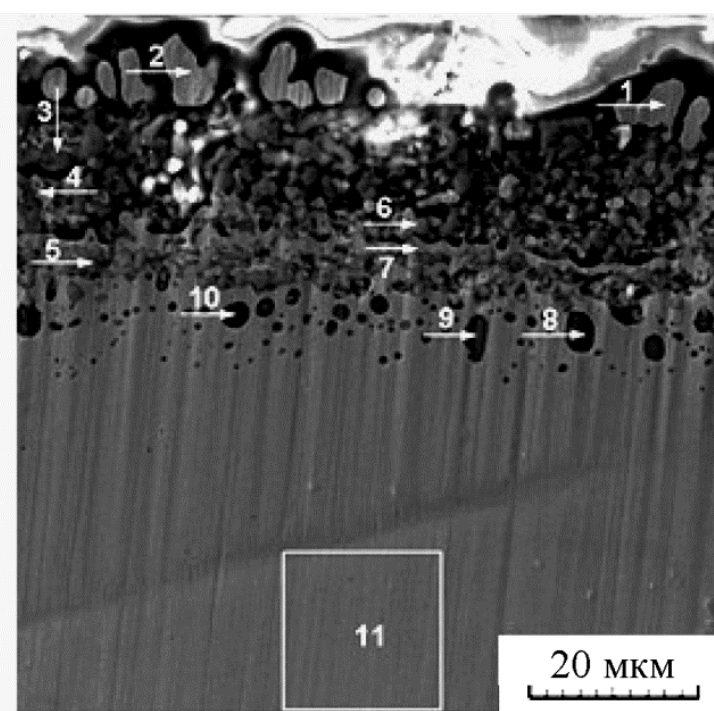

$\sigma$

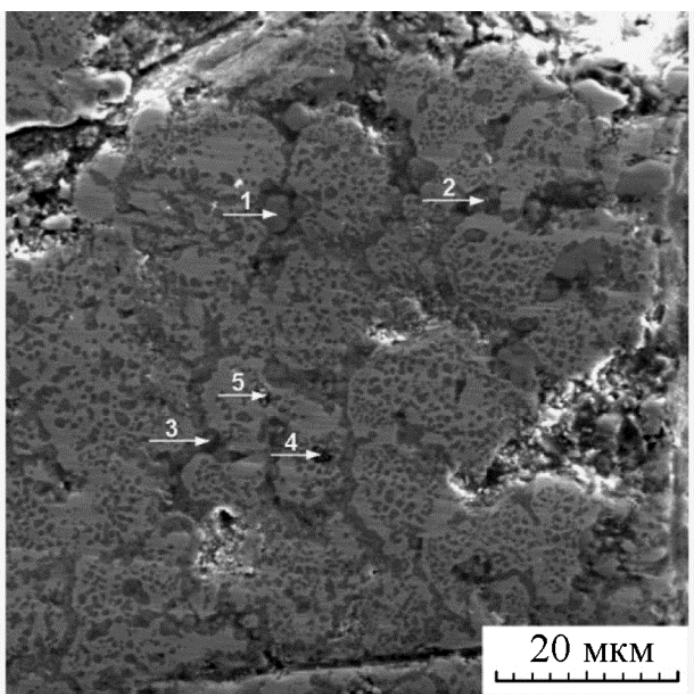

2

Рис. 4. Окисление поверхности фрагментов теплообменника из стали 12Х15Г9НД: $a$ - внешний вид поперечного сечения фрагмента диффузора дыма; $\sigma$ - окисление внутренней поверхности диффузора дыма; в - окисление поверхности панели 1 ; 2 - окисление поверхности панели 2

При проведении операций холодного формоизменения (штамповка, вытяжка) следует учитывать более высокую способность к наклепу хромомарганцевого аустенита (стали марки 10X14Г14Н4T) по сравнению с хромоникелевым (сталь марки 08X18H10T). Эрозионная стойкость этих сталей будет определяться качеством обработки поверхности (с увеличением показателей шероховатости возрастает вероятность адгезионного налипания частиц газового потока на поверхность), а также скоростью роста оксидной пленки. Более высокое содержание хрома и никеля в стали 08X18Н10Т по сравнению со сталью марки 10Х14Г14НТ явно позволит получать на поверхности рекуператора оксидную пленку с достаточно высокими защитными свойствами в условиях воздействия скоростного газового потока. Следует пом- 
нить, что при эксплуатации хромоникельмарганцевых сталей (например 10Х14Г14НТ) в присутствии серосодержащих газов марганец будет активно взаимодействовать с серой с образованием сульфидов $[5,12,13]$, обедняя тем самым аустенит. При этом может возникнуть опасность появления ферритной составляющей в структуре стали, что отрицательно повлияет на ее коррозионную стойкость, особенно на склонность к межкристаллитной коррозии.

Таблица 3 - Химический состав участков

\begin{tabular}{|c|c|c|c|c|c|c|c|c|c|}
\hline \multirow{2}{*}{$\begin{array}{c}\text { № } \\
\text { участ } \\
\text { ка }\end{array}$} & \multicolumn{9}{|c|}{ Химические элементы, масс. \% (основа - Fe) } \\
\hline & $\mathrm{C}$ & $\mathrm{Cr}$ & Mn & $\mathrm{Ni}$ & $\mathrm{Cu}$ & $\mathrm{S}$ & $\mathrm{O}$ & $\mathrm{Si}$ & Примечание \\
\hline \multicolumn{10}{|c|}{ Участки анализа (рис. 4 б) } \\
\hline 1 & 1,8 & 1,1 & 0 & 0 & 1,8 & 0 & 0 & 0,8 & \multirow{2}{*}{$\begin{array}{c}\text { Сталь } \\
\text { измененного } \\
\text { состава }\end{array}$} \\
\hline 2 & 2,4 & 1,4 & 0 & 0 & 2,2 & 0 & 0 & 0 & \\
\hline 3 & 0 & 33,8 & 5,1 & 0 & 6,7 & 1,5 & 27,9 & 0,7 & \multirow{2}{*}{$\mathrm{Cr}_{2} \mathrm{O}_{3}, \mathrm{MnO}, \mathrm{MnS}$} \\
\hline 4 & 0 & 17,4 & 4,5 & 1,7 & 1,1 & 0 & 23,2 & 2,2 & \\
\hline 5 & 2,5 & 31,7 & 15,3 & 0,6 & 0 & 0 & 18,7 & 0,6 & Оксиды + углерод \\
\hline 6 & 0 & 15,0 & 4,2 & 1,5 & 1,0 & 0 & 14,5 & 3,5 & Оксиды \\
\hline 7 & 2,1 & 17,6 & 8,1 & 1,6 & 1,2 & 19,4 & 10,7 & 0,4 & $\mathrm{MnS}, \mathrm{Cr}_{2} \mathrm{O}_{3}, \mathrm{MnO}$ \\
\hline 8 & 0 & 14,9 & 12,8 & 1,6 & 2 & 0 & 31,7 & 22,9 & Сталь + оксиды \\
\hline 9 & 2,2 & 3,7 & 34,9 & 0 & 0 & 1,4 & 25,5 & 16,1 & Оксиды + углерод \\
\hline 10 & 0 & 21,4 & 20,8 & 0 & 0 & 0 & 26,2 & 0,8 & $\mathrm{Cr}_{2} \mathrm{O}_{3}, \mathrm{MnO}$ \\
\hline 11 & 0,2 & 14,0 & 8,7 & 1,1 & 1,4 & 0 & 0 & 0,4 & Сталь \\
\hline 12 & 84,6 & 0 & 0 & 0 & 0 & 0 & 10,3 & 0 & Углерод \\
\hline \multicolumn{10}{|c|}{ Участки анализа на рис. 4 в } \\
\hline 1 & 0 & 11,1 & 43,7 & 0 & 1,0 & 0 & 2,8 & 0,5 & Сталь \\
\hline 2 & 1,4 & 8,5 & 0,6 & 1,6 & 0 & 0,13 & 18,5 & 0,2 & \multirow{2}{*}{$\mathrm{Cr}_{2} \mathrm{O}_{3}+$ углерод } \\
\hline 3 & 3,7 & 3,3 & 0,6 & 1,0 & 1,3 & 0 & 2,2 & 0,1 & \\
\hline 4 & 0 & 1,9 & 12,4 & 0 & 1,4 & 0 & 21,5 & 1,4 & $\mathrm{MnO}+\mathrm{Cr}_{2} \mathrm{O}_{3}$ \\
\hline 5 & 0 & 39,7 & 20,4 & 0 & 0 & 0 & 24,7 & 0,8 & $\mathrm{Cr}_{2} \mathrm{O}_{3}+\mathrm{MnO}$ \\
\hline \multicolumn{10}{|c|}{ Участки анализа на рис. 4 г } \\
\hline 1 & 1,5 & 11,8 & 20,7 & 0 & 0 & 0 & 22,2 & 0,8 & $\mathrm{MnO}+\mathrm{Cr}_{2} \mathrm{O}_{3}$ \\
\hline 2 & 2,3 & 24,5 & 16,3 & 0 & 0 & 0 & 23,9 & 0,4 & \multirow{4}{*}{$\begin{array}{c}\text { Углерод, } \mathrm{Cr}_{2} \mathrm{O}_{3}, \\
\mathrm{MnO}\end{array}$} \\
\hline 3 & 2,5 & 13,1 & 17,2 & 0 & 0,7 & 0 & 22,2 & 1,6 & \\
\hline 4 & 49,9 & 6,6 & 2,6 & 0,4 & 0,8 & 0 & 9,6 & 0 & \\
\hline 5 & 46,6 & 4,8 & 1,7 & 0,7 & 1,9 & 0,1 & 7,4 & 0 & \\
\hline
\end{tabular}

\section{4. Выводы}

Во всех исследованных фрагментах теплообменника, изготовленных из стали $12 \mathrm{X} 15$ ГОНД, после эксплуатации в условиях металлургического цеха произошло интенсивное окисление поверхности с образованием оксидов хрома и марганца, а также сульфидов марганца. Для коллектора газохода характерно сквозное образование оксидов и сульфидов по границам аустенитного зерна по всей толщине.

Для фрагмента коллектора газохода характерно науглероживание стали, что привело к изменению структуры с аустенитной на мартенситную для фрагмента коллектора газохода. Размер аустенитного зерна соответствовал баллу 3-7 ГОСТ 5639-82, что свидетельствует 
о высоких рабочих температурах теплообменника. Интенсивное окисление границ аустенитного зерна материала одной из панелей подтверждает перегрев стали.

Сталь марки 12X15Г9НД (AISI 201) при всех ее достоинствах нецелесообразно применять для изготовления промышленных теплообменников, эксплуатируемых в металлургическом производстве, поскольку стали этого класса не предназначены для эксплуатации при высоких температурах в окислительных и серосодержащих средах. Для изготовления пластинчатых оребренных рекуператоров в большей степени подходит сталь марки 08X18Н10Т, обладающая удовлетворительной коррозионной стойкостью, хорошо свариваемая, не склонная к ножевой и межкристаллитной коррозии на участках сварки. Однако следует ограничивать максимальную рабочую температуру рекуператора и избегать значений $900{ }^{\circ} \mathrm{C}$ и выше. Оптимальной рабочей температурой является температура $600{ }^{\circ} \mathrm{C}$.

\section{Благодарность}

Работа выполнена на оборудовании ЦКП «Пластометрия» ИМАШ УрО РАН в соответствие с государственныл заданием по теме № АAАA-A18-118020790145-0. ваний.

Авторы выражают благодарность Е. Б. Трушиной за помощь в проведении исследо-

\section{Список литературы}

1. Ульянин Е. А. Коррозионностойкие стали и сплавы : справочник. - М. : Металлургия, 1991. - 255 с.

2. Туфанов Д. Г. Коррозионная стойкость нержавеющих сталей, сплавов и чистых металлов : справочник. - М. : Металлургия, 1990. - 320 с.

3. Бабаков А. А., Приданцев М. В. Коррозионностойкие стали и сплавы. - М. : Металлургия, 1971. - $318 \mathrm{c}$.

4. Коррозионностойкие, жаростойкие и высокопрочные стали и сплавы : справочное издание / А. П. Шлямнев, Т. В. Свистунова, О. Б. Лапина, Н. А. Сорокина, В. И. Маторин, В. И. Столяров, С. Д. Боголюбский, Н. Н. Козлова, А. Ф. Ендерал. - М. : Интермет инжиниринг, 2000. - 232 с. - ISBN: 5-89594-028-5.

5. Stainless Steels: an Introduction and their Recent Developments / ed. by Ki Leuk Lai, J., Kin Ho Lo, Chan Hung Shek. - Bentham Science Publishers, 2012. - DOI: 10.2174/97816080530561120101. $168 \mathrm{p}$.

6. Brooks J. A. Weldability of high N, high Mn austenitic stainless steel // Welding Research Supplement. - 1975. - P. 189-195.

7. Uggowitzer P. J., Magdowski R., Speidel M. O. Nickel Free High Nitrogen Austenitic Steels // ISIJ International. - 1996. - Vol. 36, No. 7. - P. 901-908. - DOI: 10.2355/isijinternational.36.901.

8. Гольдштейн М. И., Грачев С. В., Векслер Ю. Г. Специальные стали. - М. : Изд-во МИСиС, 1999. - 408 с.

9. Robino C. V., Michael J. R., Maguire M. C. The solidification and weld metallurgy of galling resistant stainless steels // Welding Journal. - 1998. - Vol. 77 (11). - P. 446-457.

10. Hot ductility of austenite stainless steel with a solidification structure / F. Tehovnik, F. Vodopivec, L. Kosec, M. Godec // Materiali in Tehnologije. - 2006. - Vol. 40. - P. 129-137.

11. Phase changes of Fe-20Mn-13Cr-3Co/1.2Ti alloys during solution nitriding / J. H. Sung, D. W. Joo, I. S. Kim, C. Y. Kang, J. H. Sung // Met. Mater. Int. - 2005. - Vol. 11. - P. 157-163. DOI: $10.1007 / \mathrm{BF} 03027460$.

12. Williamson D. L., Davis J. A., Wilbur P. J. Effect of austenitic stainless steel composition on low-energy, high-flux, nitrogen ion beam processing // Surf. Coat. Technol. - 1998. Vols. 103-104. - P. 178-184. - DOI: 10.1016/s0257-8972(98)00389-2. 
13. Microstructure, corrosion and tribological behaviour of plasma immersion ion-implanted austenitic stainless steel / M. Samandi, B. A. Shedden, D. I. Smith, G. A. Collins, R. Hutching, J. Tendys // Surf. Coat. Technol. - 1993. - Vol. 59. - P. 261-266. - DOI: 10.1016/02578972(93)90094-5.

14. Correlation between PIII nitriding parameters and corrosion behaviour of austenitic stainless steels / S. Mändl, D. Manova, H. Neumann, M. T. Pham, E. Richter, B. Rauschenbach // Surface \& Coatings Technology. - 2005. - Vol. 200. - P. 104-108. - DOI: 10.1016/J.SURFCOAT.2005.02.084.

15. Hansen M., Anderko K. Constitution of binary alloys. - New York, Toronto : McGraw Hill Book Co., Inc., 1958. - P. 670-675.

16. Справочник металлиста : в 5 томах / под ред А. Г. Рахштадта и В. В. Бромтрема. М. : Машиностроение, 1976. - 720 с. - Т. 2.

17. Материалы в машиностроении. Выбор и применение : справочник в пяти томах / под общ. ред. И. В. Кудрявцева. - Т. 3 : Специальные стали и сплавы / под ред. Ф. Ф. Химушина. М. : Машиностроение, 1968. - 217 с.

18. Стали и сплавы. Марочник : справ. изд. / под ред В. Г. Сорокина и М. А. Гервасьева. М. : Интермет Инжиниринг, 2003. -608 с.

19. Phase changes of $\mathrm{Fe}-20 \mathrm{Mn}-13 \mathrm{Cr}-3 \mathrm{Co} / 1.2 \mathrm{Ti}$ alloys during solution nitriding / J. H. Sung, D. W. Joo, I. S. Kim, Chang Yong Kang \& Jang Hyun Sung. - Met. Mater. Int. - 2005. - Vol. 11. P. 157-163. - DOI: 10.1007/BF03027460.

20. Ключ сталей. Изготовление и поставка : справочник / пер с нем. - М. : Интермет Инжиниринг, 2001. - 734 с.

21. Ning Liu, Zhonggang Deng, Menggen Huang. Effect of heat treatment on microstructure and mechanical properties of martensitic-ferritic stainless steel containing $17 \% \mathrm{Cr}$ and $2 \% \mathrm{Ni} / /$ Materials Science and Technology. - 1991. - Vol. 7. - P. 1057-1062. - DOI: 10.1179/mst.1991.7.11.1057.

22. Металлография железа (с атласом микрофотографий) / под ред. Ф. Н. Тавадзе; пер. с англ. 3. Ш. Херодинашвили, Л. П. Даниленко. - Т. 3 : Кристаллизация и деформация сталей. - М., 1972.

23. Энгель Л., Клингеле Г. Растровая электронная микроскопия. Разрушение : справочник / пер. с нем. - М. : Металлургия, 1986. - 232 с. 